presumed lesion exists-namely, the front part of the left brain. The history, age, and good general health of the patient may fairly be held to negative the suspicion of syphilitic growth, aneurism, or cancer. Having thus elininated most of the causes of cerebral diseases, the existence of some form of tumour remains to be considered. The ordinary forms of tumour do not occur in young subjects. There are, however, two adventitious products which are often found in the brain at an early age-viz., tubercle and gliomata. To one of these causes I am disposed to attribute the symptoms, and preferably to the former, both because it is the more common, and because the idea derives support from the history of a near relative succumbing to a probably tubercular affection of the lung. The comparatively sudden occurrence of the symptoms was probably due to thrombosis of the left cerebral artery, resulting from inflammatory activity in the immediate vicinity of the deposit.

Watton, Norfolk.

\section{A CASE OF APHASIA; RECOVERY.}

BY JAMES COPLAND, M.D., C.M. ONE OF THE HONORARY PHYSICIANS OF THE DUNEDIN HOSPITAL.

THE patient, a man of sixty-five years of age, long subject to weakness and irregularity of the heart, had otherwise enjoyed good health, and was of temperate and regular habits. On March 14th, 1880, at 10.30 P.M., soon after retiring to bed, he was found speechless. He had been moving about as usual during the day, and had attended church in the evening. A friend who walked home with him had observed that he showed some difficulty in speaking. I learned that for a week previous he had appeared duller than usual, and had said he felt "there was something working on him." Shortly before this he had received a fright from a horse kicking up near him, the blow of which he narrowly escaped. I saw him about 11 P.M. He quite understood what was said to him, but his expression was duller than usual; the right pupil was dilated and fixed, and the only word he could speak was "no." When asked a question which he wished to answer in the affirmative, he said "no," but with a significant movement of his head. There was facial paralysis on the right side, but not so complete as in paralysis of the portio dura of the seventh nerve. He could close the eye, but could not whistle. The tongue, when protruded, turned slightly towards the right side. The right arm and leg were partially paralysed. He could move the arm in a weakly manner, but could not direct its movements as he desired. The pulse ranged about 60 , with occasional intermissions. A small blister was applied behind the right ear, cold to the head, the feet kept warm, and five grains of calomel and ten grains of rhubarb were administered. A mixture containing carbonate of ammonia and spirits of chloroform was given every four hours. The bowels acted twice before 10 o'clock next morning. The symptoms remained the same. In the evening, a small blister was applied behind the left ear. On the 16th, in consultation with Dr. Gillies, solution of strychnia in two-minim doses was ordered in a mixture containing nitrous, sulphuric, and chloric ether, and sinapisms were applied to the calves. Two days afterwards the strychnia was increased to threeminim doses. Beef-tea and two glasses of spirits, in divided doses, were taken daily. Treatment of a similar kind was continued throughout. On the 17 th he was asked by the nurse to write with a pencil, but on attempting it he found he could not direct it as he wished. On the 20 th in my presence he wrote his name, in a very feeble and imperfect way, omitting some of the letters. On the evening of the 23rd he seemed duller than before, and the right pupil, which had returned to its normal state, was dilated, but these symptoms passed off on the following day. The strychnia was now increased to four-minim doses, which was continued during the next fortnight, with great benefit, the bowels acting regularly every day. The only purgatives given after the night of the attack were two powders, each containing two grains and a half of calomel and five grains of rhubarb, which were administered within the first ten days. On the 25th, on testing whether he could pronounce any word beside "no," he succeeded with " on." In attempting " come" he could only say "om." The power of swallowing and the bodily health generally are much improved.
The arm is regaining its strength in grasping, and he can move the hand in every direction. He shows no improve ment in writing with a pencil, and is quickly wearied with the effort. He sat up after this for an hour or two dailv in an arm-chair, and on April 3rd, with some assistance, had his clothes put on. On the 4 th, exactly three weeks after the attack, he spoke a few words, which were intelligible, although not very distinctly articulated. On showing him some words in large type he read them correctly. 6th : Speech slowly improving; medicine and diet as before ; has been walking out daily in the garden since the 4 th ; can use knife and fork in cutting a potato.-11th: Speaks with greatfreedom; can use the right hand for allordinary purposes but it is not so strong as the other; the sight, which was impaired, has returned to its normal state. - 19th: The cold cloth which he has kept applied to his head ever since the attack is discontinued. - 23rd : Is able to read a newspaper with understanding, but has difficulty in reading it aloud. He does not remember readily the sound of the words, although he can speak them easily when pronounced in his hearing.

From this time there was gradual improvement in strength which was assisted by the use of digitalis, iron, \&c. By May 18th his general health seemed to be as good as before the attack. He had no difficulty in speaking distinctly. Although able to read a newspaper so as to understand it he still felt difficulty in reading aloud, as he could not remember readily the sounds of the words. The subsequent history of this case up to the present time (February, 1883) has been most satisfactory. He has followed his quiet em ployment (chiefly out of doors) in the enjoyment of good health, with one or two brief interruptions. On Dec. 18th 1880, he was seized with a shivering fit, and on examining the heart I found at the apex a strong blowing murmur accompanying the first sound, and completely covering the second. It was heard less distinctly towards the base. Pulse 104. A mixture of aromatic spirit of ammonia, solution of acetate of ammonia, tincture of digitalis, and sedative solution of opium was ordered. In a day or two the murmur disappeared, and he was in his usual state of health On May 2nd, 1881, he felt a strange sensation, as if the side of his head were compressed, then his head was thrown backwards, and he fell to the ground in a state of uncon sciousness. He was alone and unobserved at the time, and probably remained unconscious about half an hour. $\mathrm{He}$ stated that he had experienced a similar sensation before this occasion, passing up the right side of his head, but without producing unconsciousness. - Feb. 1883 : $\mathrm{He}$ continues to enjoy good health, and follows his usual em ployment, although his heart is weak and he is unable to bear much heat, exertion, or excitement. There is no appreciable change in his power of conversing from what it was before the attack. He is able to read with ease, but feels any attempt at writing irksome, and seldom makes it. Sometimes he can write his own name fairly, but at other times he has much greater difficulty, and omits some of the letters, showing his memory to be impaired. With this exception his recovery from the cerebral lesion which produced aphasia may be regarded as complete. A stranger unaware of what had occurred would be unable to detect any trace of it.

The satisfactory issue of the case may, I trust, assist others in forming their prognosis in similar cases. I would only venture to add that trom the beneficial effects of strychnia and digitalis experienced in this case these remedies appear to be worthy of more extensive application than they generally receive.

Dunedin, New Zealand.

\section{PROSTATIC GOUT.}

BY REGINALD HARRISON, F.R.C.S., SURGEON TO THE LIVERPOOL ROYAL INFIRMARY.

I PROPOSE offering some observations on an inflammatory condition of the prostate which, though never, I believe, terminating in abscess, is attended with much suffering, and not unfrequently leads to further consequences. Though this gland is not so often selected for acute gouty manifestations as the ball of the great toe and the vicinity of some of the smaller joints, yet cases are sufficiently common to make the subject deserving of comment, and particularly in reference to one or two points. Gouty prostatitis, so far as I have observed it, occurs in persons who, though having a 
gouty diathesis, either hereditary or acquired, have previously remained free from the more ordinary attacks of this disorder. Its occurrence is of ten assigned to catching cold, getting wet, or sitring upon damp seats. Like gout acutely affecting the great toe, the attack usually comes on at night, the patient experiencing severe pain, which he refers to the perineum, and not unfrequently likens to a hot cork. Though painful, the desire to micturate is irresistible, and is accompanied with spasms, which often render any attempt to retain urine, even while the patient is getting out of bed, almost impossible. Sympathetic pain is at the same time experienced in the groin, or in one or both testicles, rendering the latter extremely seusitive to the touch. Exploration of the rectum with the finger-a necessary examination, which is sometimes so painful as to call for an anæsthetic-shows the prostate to be both tense and teader. During the day the symptoms generally abate, to recur at night. Like the analogous manifestation in the great toe, these acute prostatic attacks are not usually of long duration, as they merge into a chronic form, which will presently be noticed. The urine is loaded with lithates, and is invari ably of an acid and irritating character. After an acute attack the prostate is often left excessively sensitive, and this is a point worthy of special consideration. After an acute attack of gout in the foot the limb is tender, and the person is more or less lame. So with the prostate: it remains sensitive, and the patient dreads to call forth sufficient muscular force to completely empty his bladder. In fact, he lets his urine dribble off voluntarily, and retains a portion of it, so as to form a sort of water-bed behind his prostate. In this way he wards off from his sensitive gland the last and most painful efforts of each act of micturition. Watch a patient, with a prostate tender from gout, pass water, and the manner in which he cautiously eases off the pressure as the act is about to close is very significant. I have eatisfied myself on several occasions that a degree of retention was thus caused by passing a rubber catheter and removing an ounce or so of urine, when it was believed by the patient that he had emptied his bladder.

It is generally conceded that an hypertrophied prostate which causes nrine to be constantly retained within the bladder is a condition favouring the formation of stone. I have thus endeavoured to show that the urine of the gouty is not nnfrequently submitted to similar conditions, but under different circumstances. May not this consideration explain why the inorganic elements of the urine of one gouty person concrete, whilst in another they do not? Is the shortness and dilatability of the female urethra sufficient to explain the rarity of stone in women, even in those of a markedly gouty diathesis?

In the treatment of acute prostatic gout there are one or two points to which prominence is to be given. In the first place it is always associated with a highly acid condition of the urine, and with an excess of urates as well as of uric acid. The administration of alkalies under these circumstances can hardly be regarded other than as a natural expedient. It has been stated that the neutralisation of these urine-salts by the alkali is little else than masking the disorder, as the cause of it still remains untouched. Bat there is a mechanical aspest to this question which must not be passed by entirely without notice. One effect of the administration of alkalies upon such urine is not only attended with a marked disappearance of the urate salts from the urine, but careful mieroscopical ohservation has shown that the use of alkalies is frequently followed by a change in crystalline form, which is of considerable advantage to the patient, though he may still continue to void urates. When the degree of vesical and urethral irritation was intense, I have seen all this disappear coincident with a change in the crystalline form, being brought ahout by some artificial means. It is interesting to no: ice the relation the mucus that is deposited in the urine holds to the kind and quantity of the crystalline forms existing in health as well as in disease in this excretion. Some crystals of uric-acid salts, for example, excite an immense discharge of this mucus. Such salts seem to act uprin the urin rry apparatus much in the same way as a foreign bodv in the eye stimulates a flow of the natural secretion, and readers it inordinate so long as the irritant remains there. Can it be dnubted that the means we possess of influencing the urinary mucus through changes in the urine salts we are capable of artificially effecting are not important ones in relation to the subject of stone formation? Does not such a consideration take us one step further back in treating calculous disorders, or the tendency thereto, by bringing them distiactly within the scope of medicines rather than of machines?

The chronic form of the disorder, where the prostate remains tender for a cousiderable period, or until it is relieved by treatment, requires careful cousideration, as it is a far more frequent cause of residual urine than is generally supposed. Occurring, as it often does, at a period of life when byper. trophy of the gland usually takes place, the demonstration by the catheter that the bladder does not empty itself is $a$ circumstance which is sometimes received and acted upon as conclusive evidence that the time has arrived when what Sir Andrew Clark has aptly spoken of as "the catheter life" should commence. There is this important difference, however, between the residual urine of a sacculated bladder in connexion with a large prostate and that dependent on a gland which is sensitive and merely temporarily enlarged the former is benefited by catheterism, the latter is aggravated by it. The former is comparatively uninfluenced by medicines, whilst the gouty prostate which interferes with the complete emptying of the bladder is speedily relieved by those measures which belong to the department of the phy. sician rather than of the surgeon. Where the urine is rendered alkaline in the bladder by circumstances which bring about its decomposition, it is not difficult to understand how a phosphatic stone may be the result. In the view I have urged, relating to another reason for residual urine, is to be found a vesical cause for the collection and aggregation of those materials which tne urine of the gouty furnish. It has been observed by Dr. Ord, "Two-thirds of all urinary calculi are in bulk composed of or start from concretions of uric acid.

The symptoms of chronic gouty prostatitis are ofter anomalous and difficult to sum up; they may be briefly enumerated as urine habitually loaded with uric acid and urates, unnatural sensitiveness of the prostate to the touch, or even to pressure applied to the perineal region, and the presence of uncomfortable sensations referred to the reck of the bladder, as if there was a swelling, or the viscus was not emptied, the latter sensation being practically well founded. The treatment of the affection resolves itself into the employment of those general measures appropriate to the gouty diathesis, which it is not necessary for me to refer to. Iodide of potassium internally, and a mild form of counter-irritation to the perineum, will often be found very advantageous in removing prostatic tenderness. Lastly, this is a class of disorders which is often largely benefited by some spas where the diathesis is corrected by suitable diet and waters. In our own country I have found Buxton of very great service; whilst abroad there are many wateringplaces which such persons may visit with advantage. It is not always easy to recommend suitable drinks for these cases. I have found the Giesshübler Sauerbrunnen a very pleasant beverage; as imported into this country $I$ ear endorse Dr. Kraus' ${ }^{2}$ recommendation of it as "a very pleasant and refreshing drink, which invigorates the nervors.s system, removes acidity of the stomach, gently stimulates the action of the bowels, and causes a copious flow of urine thus combining the qualities of a good drinking water with those of a mild curative agent." It mixes well with red wine. Liverpool.

\section{AN UNUSUAL CASE OF CLEFT PALATE.}

\section{BY A. ERNEST MAYLARD, B.S. LOND.,}

EXTRA DISPEASARY SURGEON TO THE WESTERN INFIRMARY, GLASGOT, CLINICAL ASSISTANT TO THE PROFESSOR OF SURGERY AT TII UNIVERSTTY OF GLASGOW.

THE following case was admitted into the Western Inf $\mathrm{r}$ mary of Glasgow, under the charge of Professor Macleod, to whom $\mathrm{I}$ am indebted for permission to publish it.

The child, a male, aged four months, was brought to the infirmary with what appeared at first sight a simple uncomplicated case of left harelip, but on closer examination the following unusual condition of parts was seen. Immediately behind the cleft in the lip was a division in the alveolus, and extending back directly from this with. no deviation towards the middle line, a narrow fissure which widened out posteriorly in to a well-marked interval. On the

1 The Influence of Colloids upon Crystalline Form, p. 60.

2 The mineral water at Carlsbad. 